\title{
Experience with the HeartMate II Left Ventricular Assist Device in Patients Older than 60 Years
}

\author{
Zumrut T. Demirozu, MD, Andre Critsinelis, BS, William E. Cohn, MD, Rajko Radovancevic, MD, \\ Jonathan Ho, MD, Ruben Hernandez, MD, Jeffrey A. Morgan, MD, O. Howard Frazier, MD \\ Division of Cardiothoracic Transplantation and Circulatory Support, Baylor College of Medicine, Houston, Texas
}

\section{ABSTRACT}

Background: Advanced age is a relative contraindication for heart transplantation, but no age cutoff has been defined for patients receiving mechanical circulatory support.

Methods: Between November 1, 2003 and November 1, 2012, we implanted the HeartMate II (HMII) left ventricular assist device (LVAD) in 319 patients. One hundred seven patients (89 men, 18 women) were over 60 years old (mean, $66 \pm 4$ years; range, $61-78$ years) and received the HMII as a bridge to transplantation $(\mathrm{n}=45)$ or as destination therapy $(n=62)$. We evaluated their experience by performing a retrospective analysis.

Results: Seventy-two patients had ischemic cardiomyopathy, and 34 had idiopathic cardiomyopathy. Three patients (2.8\%) already had a HeartMate XVE LVAD; 54 (50.5\%) were receiving intra-aortic balloon pump support; 52 (48.6\%) had undergone a previous cardiac procedure; and $9(8.4 \%)$ had received renal replacement therapy (RRT) (continuous venovenous hemofiltration, hemodialysis, or both) before HMII implantation. The median duration of HMII support was 313 days (range, 1-3339 days). After device implantation, 36 patients (33.6\%) had gastrointestinal bleeding, 24 (23\%) required RRT, $18(17.5 \%)$ had ventricular arrhythmias, and 24 (22.4\%) had LVAD-related infections, and $9(8.4 \%)$ had right ventricular failure requiring mechanical support, and 28 (26.2\%) had neurologic complications. The actual survival rate was $69 \%$ at 6 months, $63 \%$ at 1 year, and $54 \%$ at 2 years. Eighty-one patients died; 9 are still receiving HMII support; and 17 are alive after heart transplantation.

Conclusions: Older patients can benefit from LVAD therapy, and advanced age should not preclude LVAD implantation.

\section{INTRODUCTION}

Heart transplantation is the gold-standard therapy for patients with end-stage heart failure, but its utility is

Received November 13, 2018; received in revised form fanuary 26, 2019; accepted fanuary 29, 2019.

Correspondence: Feffrey A. Morgan, MD, Professor and Chief, Division of Cardiothoracic Transplant and Circulatory Support, Baylor College of Medicine, 6770 Bertner Avenue, Suite C-355N, Houston, TX 77030; 1-832-355-3000 (e-mail: feffrey.Morgan@bcm.edu). limited by a shortage of donor organs, which results in increased wait times. Although advanced age is a contraindication for heart transplantation, there appears to be no critical age beyond which patients cannot receive mechanical circulatory support (MCS) [Deng 2001; Jurmann 2004; Huang 2006; Sandner 2009; Drews 2010; Stepanenko 2010]. Because heart transplantation is not typically a feasible option for patients with end-stage heart failure who are more than 65 years old, long-term MCS is increasingly becoming important for the care of these older patients, whose outcomes are improved after device implantation compared with alternative medical therapies [Jurmann 2004; Huang 2006; Drews 2010; Stepanenko 2010]. As with any other treatment, the effects of age and age-related comorbidities should be determined on an individual basis for older patients who have advanced heart failure and are referred for left ventricular assist device (LVAD) therapy [Jurmann 2004; Huang 2006; Sandner 2009].

We report our single-center experience with patients older than 60 years who have been supported by the continuousflow HeartMate II (HMII) LVAD (Thoratec Corporation, Pleasanton, CA, USA) for end-stage heart failure.

\section{MATERIALS AND METHODS}

Of the 319 patients with end-stage heart failure who underwent implantation of a continuous-flow HMII LVAD at our hospital between November 1, 2003 and November 1, 2012, 107 patients (89 men [83.2\%] and 18 women [16.8\%]) were aged more than 60 years (mean, $66 \pm 4$ years; range, 61-78 years). All 107 patients were included in this retrospective chart-review study. The study was approved by our center's Institutional Review Board, and informed consent for LVAD implantation was obtained from all patients.

The specific objective of this analysis was to ascertain whether outcomes in patients aged above 60 years were acceptable. Specific-outcomes metrics that were evaluated included survival, infection, renal failure, gastrointestinal bleeding, right-sided heart failure, and stroke.

Statistical comparisons were 2-sided, and laboratory data were subjected to between-subjects analysis. A $P$ value of $<.05$ was considered significant. Survival analysis for the patients continuing to receive MCS was performed by using the Kaplan-Meier method with patients censored for transplantation; log-rank test was performed to compare 5-year survival between patients greater than 60 years to those 60 and 
Table 1. Demographic and Preimplantation Characteristics*

\begin{tabular}{|c|c|c|c|}
\hline & $\begin{array}{c}>60 \text { Years } \\
n=107\end{array}$ & $\begin{array}{c}\leq 60 \text { Years, } \\
n=212\end{array}$ & $P$ \\
\hline \multicolumn{4}{|l|}{ Demographics } \\
\hline Age (years) & $66.2 \pm 4.4$ & $46.7 \pm 10.7$ & $<.001$ \\
\hline Body mass index $\left(\mathrm{m}^{2}\right)$ & $27.5 \pm 5.5$ & $29.3 \pm 7.1$ & .01 \\
\hline Body surface area $\left(\mathrm{m}^{2}\right)$ & $2.0 \pm 0.3$ & $2.1 \pm 0.5$ & .01 \\
\hline Sex & & & .23 \\
\hline Men & $89(83.2 \%)$ & $164(77.4 \%)$ & \\
\hline Women & $18(16.8 \%)$ & $48(22.6 \%)$ & \\
\hline Etiology & & & $<.001$ \\
\hline Ischemic cardiomyopathy & $72(67.3 \%)$ & $83(39.2 \%)$ & \\
\hline Idiopathic cardiomyopathy & $35(32.7 \%)$ & $128(60.4 \%)$ & \\
\hline Indication & & & .22 \\
\hline Bridge to transplantation & $45(42.1 \%)$ & $104(49.1 \%)$ & \\
\hline Destination therapy & $62(57.9 \%)$ & $107(50.5 \%)$ & \\
\hline \multicolumn{4}{|l|}{ Preimplantation Characteristics } \\
\hline Diabetes mellitus & $56(52.3 \%)$ & $76(35.8 \%)$ & .005 \\
\hline Hypertension & $73(68.2 \%)$ & $110(51.9 \%)$ & .005 \\
\hline $\begin{array}{l}\text { History of cardiac ar- } \\
\text { rhythmia }\end{array}$ & $66(61.7 \%)$ & $124(58.5 \%)$ & .58 \\
\hline AICD implantation & $14(13.1 \%)$ & $44(20.8 \%)$ & .09 \\
\hline Previous cardiac surgery & $52(48.6 \%)$ & $80(37.7 \%)$ & .08 \\
\hline Exchange from $\mathrm{HM}-\mathrm{XVE}$ & $2(1.9 \%)$ & $34(16.0 \%)$ & $<.001$ \\
\hline $\begin{array}{l}\text { HM-XVE support time } \\
\text { (days) }\end{array}$ & $589.0 \pm 165.5$ & $440.4 \pm 250.2$ & .41 \\
\hline \multicolumn{4}{|l|}{ Preimplantation support } \\
\hline Intra-aortic balloon pump & $54(50.5 \%)$ & $84(39.6 \%)$ & .07 \\
\hline TandemHeart or Impella & $14(13.1 \%)$ & $41(19.3 \%)$ & .15 \\
\hline $\begin{array}{l}\text { Preimplantation hepatic } \\
\text { dysfunction }\end{array}$ & $13(12.1 \%)$ & $37(17.5 \%)$ & .22 \\
\hline Preimplantation RRT & $9(8.4 \%)$ & $18(8.5 \%)$ & .96 \\
\hline INTERMACS Profile & & & .23 \\
\hline 1 & $16(15.0 \%)$ & $41(19.3 \%)$ & \\
\hline 2 & $47(43.9 \%)$ & $65(30.7 \%)$ & \\
\hline 3 & $29(27.1 \%)$ & $59(27.8 \%)$ & \\
\hline 4 & $10(9.3 \%)$ & $22(10.4 \%)$ & \\
\hline 5 & $0(0.0 \%)$ & $3(1.4 \%)$ & \\
\hline 6 & $0(0.0 \%)$ & $0(0.0 \%)$ & \\
\hline 7 & $3(2.8 \%)$ & $2(0.9 \%)$ & \\
\hline \multicolumn{4}{|l|}{ Hemodynamic values } \\
\hline $\begin{array}{l}\text { Left ventricular ejection } \\
\text { fraction }(\%)\end{array}$ & $22.0 \pm 2.9$ & $21.5 \pm 3.3$ & .16 \\
\hline LVEDD & $6.6 \pm 1.0$ & $6.6 \pm 1.4$ & .93 \\
\hline Cardiac index $\left(\mathrm{L} / \mathrm{min} / \mathrm{m}^{2}\right)$ & $2.0 \pm 0.6$ & $1.9 \pm 0.6$ & .14 \\
\hline
\end{tabular}

Table 1. [Continued]

\begin{tabular}{|c|c|c|c|}
\hline & $\begin{array}{c}>60 \text { Years, } \\
n=107\end{array}$ & $\begin{array}{c}\leq 60 \text { Years, } \\
n=212\end{array}$ & $P$ \\
\hline Cardiac output (L/minute) & $3.4 \pm 1.8$ & $3.1 \pm 1.9$ & .18 \\
\hline $\begin{array}{l}\text { Pulmonary capillary wedge } \\
\text { pressure }(\mathrm{mmHg})\end{array}$ & $24.2 \pm 10.9$ & $26.6 \pm 10.9$ & .11 \\
\hline $\begin{array}{l}\text { Mean pulmonary artery } \\
\text { pressure }(\mathrm{mmHg})\end{array}$ & $35.5 \pm 11.3$ & $37.2 \pm 12.1$ & .27 \\
\hline $\begin{array}{l}\text { Central venous pressure } \\
(\mathrm{mmHg})\end{array}$ & $12.3 \pm 7.7$ & $12.4 \pm 7.3$ & .94 \\
\hline \multicolumn{4}{|l|}{ Laboratory values } \\
\hline White cell count (mm3) & $9.2 \pm 4.1$ & $9.6 \pm 4.7$ & .42 \\
\hline Platelets $\left(\mathrm{mm}^{3}\right)$ & $197.1 \pm 95.5$ & $210.6 \pm 91.2$ & .23 \\
\hline Hemoglobin (g/dL) & $11.6 \pm 2.0$ & $11.5 \pm 2.2$ & .74 \\
\hline $\begin{array}{l}\text { Prothrombin time (sec- } \\
\text { onds) }\end{array}$ & $13.2 \pm 4.1$ & $13.9 \pm 7.5$ & .34 \\
\hline $\begin{array}{l}\text { International normalized } \\
\text { ratio }\end{array}$ & $1.2 \pm 0.4$ & $1.4 \pm 1.0$ & .06 \\
\hline $\begin{array}{l}\text { Partial thromboplastin time } \\
\text { (seconds) }\end{array}$ & $37.5 \pm 15.2$ & $40.8 \pm 17.2$ & .13 \\
\hline Sodium (mEq/L) & $135.7 \pm 4.5$ & $135.4 \pm 4.6$ & .64 \\
\hline $\begin{array}{l}\text { Blood urea nitrogen } \\
(\mathrm{mg} / \mathrm{dL})\end{array}$ & $35.0 \pm 20.2$ & $29.3 \pm 18.1$ & .01 \\
\hline Creatinine $(\mathrm{mg} / \mathrm{dL})$ & $1.6 \pm 0.9$ & $1.4 \pm 0.8$ & .23 \\
\hline Albumin $(\mathrm{g} / \mathrm{dL})$ & $3.5 \pm 0.6$ & $4.5 \pm 4.2$ & .001 \\
\hline Total bilirubin (mg/dL) & $1.6 \pm 2.3$ & $1.9 \pm 2.7$ & .37 \\
\hline $\begin{array}{l}\text { Alanine aminotransferase } \\
(\mathrm{U} / \mathrm{L})\end{array}$ & $91.1 \pm 230.7$ & $78.5 \pm 151.6$ & .61 \\
\hline $\begin{array}{l}\text { Aspartate aminotransferase } \\
(\mathrm{U} / \mathrm{L})\end{array}$ & $73.4 \pm 117.7$ & $72.6 \pm 180.0$ & .96 \\
\hline $\begin{array}{l}\text { Lactate dehydrogenase } \\
(\mathrm{U} / \mathrm{L})\end{array}$ & $353.9 \pm 263.6$ & $359.5 \pm 264.8$ & .87 \\
\hline
\end{tabular}

* Results are presented as mean + standard deviation, or number of patients (\%). AICD, automatic implantable cardioverter-defibrillator; HM-XVE, HeartMate XVE left ventricular assist device; RRT, renal replacement therapy; LVEDD, left ventricular end diastolic diameter.

younger. Cox proportional hazards analysis was performed on preoperative characteristics to determine independent predictors of mortality. Inclusion criteria for variables in our Cox model were as follows: univariate Cox proportional hazards analysis was performed on all preoperative variables. Those variables with $P<.20$ in univariate analysis were included in our final multivariate model. Variables with variance inflation factor $>10$ were excluded from our model because of the introduction of multicollinearity. All analyses were performed with R 3.0.2 (Auckland, New Zealand) or Stata 13 (College Station, TX, USA) statistical softwares. Continuous variables are presented as the mean value \pm standard deviation. Adverse 


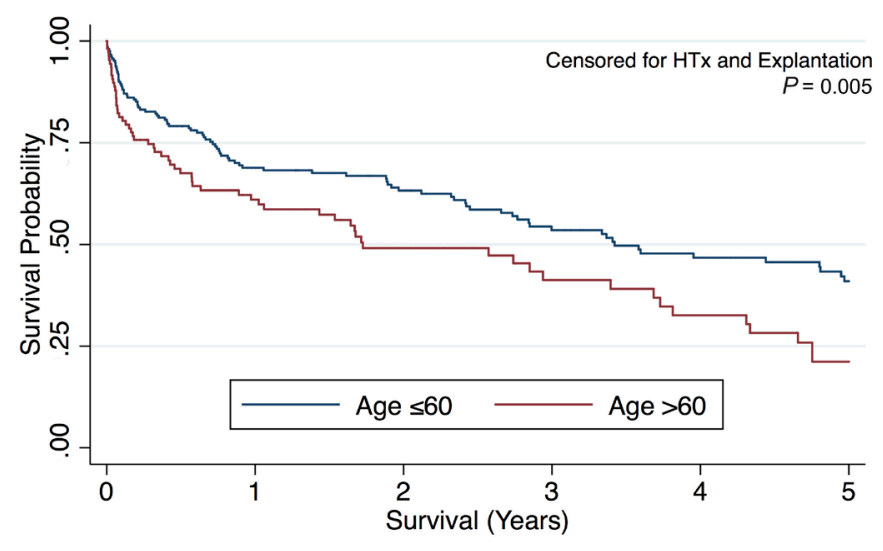

Figure 1. Kaplan-Meier survival analysis for HeartMate II recipients aged older than 60 and younger than 60 years.

events are presented as percentages of patients who had an event and as events per patient-year.

\section{RESULTS}

Table 1 shows the preimplantation and demographic characteristics of the 107 patients.

The LVAD was implanted as a bridge to transplantation in 45 patients and as destination therapy in 62 patients. Before device implantation, all patients were in New York Heart Association (NYHA) functional class IV or IIIB and were receiving maximal medical treatment, including intravenous inotropic support. Seventy-two patients $(67.3 \%)$ had ischemic cardiomyopathy, and 35 (32.7\%) had idiopathic cardiomyopathy. Sixteen (15.0\%) patients were Interagency Registry for Mechanically Assisted Circulatory Support (INTERMACS) profile 1 at the time of implantation; 47 (43.9\%) patients were INTERMACS profile $2 ; 29$ (27.1\%) patients were INTERMACS profile 3; 10 (9.3\%) patients were INTERMACS profile 4 ; and 3 (2.8\%) were INTERMACS profile 7 . Fifty-two $(48.6 \%)$ of the patients had undergone previous cardiac surgery; $54(50.5 \%)$ were being supported by an intra-aortic balloon pump (IABP); and 14 (13.1\%) were being supported by a TandemHeart (Cardiac Assist Inc., Pittsburgh, PA, USA) or an Impella (Abiomed, Danvers, MA, USA) ventricular assist device. Two patients $(1.9 \%)$ had a HeartMate (Abbott Inc., Chicago, IL) extended-lead vented electric (XVE) LVAD, and the median time before exchange to an HMII LVAD in these cases was 494 (range, 472-706) days.

Compared to HMII recipients aged less than or equal to 60 years, recipients greater than 60 had lower body mass index and body surface area $(P=.01$ for both) were more common to have ischemic etiology $(P<.001)$, had a higher incidence of diabetes mellitus and hypertension ( $P=.005$ for both), higher blood urea nitrogen levels $(P=.01)$, and lower albumin levels $(P=.001)($ Table 1$)$.

Following HMII implantation, 9 patients had a Levitronix CentriMag pump (Levitronix, Waltham, MA, USA) placed because of right-sided heart failure; 7 of these 9 patients had

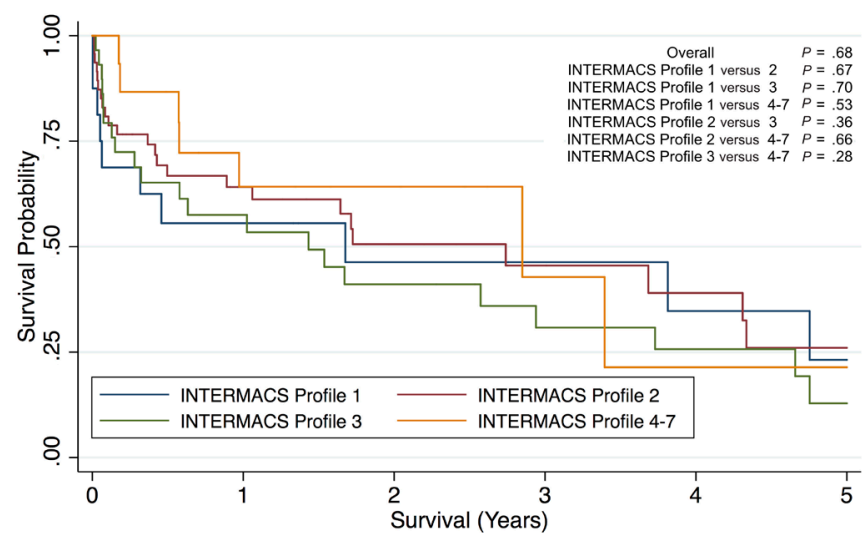

Figure 2. Kaplan-Meier survival analysis for patients aged older than 60 years, stratified by preoperative INTERMACS profile.

previously undergone a cardiac operation, and 4 had received IABP support. Twenty-eight patients had a concomitant procedure (mitral valvuloplasty, aortic valve replacement, left ventricular aneurysm resection, or coronary artery bypass grafting); 9 of these patients had previously undergone a cardiac procedure. During HMII implantation, 12 of the 13 patients with hepatic dysfunction had a liver biopsy.

The median duration of support with the HMII LVAD was 313 days (range, 1-3339 days). Twenty-eight patients underwent heart transplantation within a median of 473.5 days (range, 82-1006 days). One-year survival for heart transplant recipients was $75 \%(21 / 28)$. Sixty-six patients died within a median of 174 days (range, 1-3073 days). The 6-month survival rate was $69 \%(74 / 107)$. The 1 -year survival rate was $63 \%(67 / 107)$ (Figure 1). The 2-year survival rate was 54\% (58/107). All the patients who were discharged home were in NYHA functional class I. The most frequent cause of death was multiorgan failure resulting from septic complications and right-sided heart failure. When comparing survival between patients aged above and below 60 years at the time of implantation, patients older than 60 years had significantly worse 5 -year survival $(P=.005)$. Cox proportional hazards analysis demonstrated that age $>60$ years was an independent predictor of mortality $(P=.006$, Table 2$)$.

Biochemical and hematologic data were analyzed with regard to end-organ function. The white blood cell count and the aspartate aminotransferase, alanine aminotransferase, serum total bilirubin, and albumin levels gradually returned to normal during the 12-month follow-up period (Table 3).

Compared with the 26 survivors, the 81 patients who died had higher creatinine $(1.6 \pm 1.0$ versus $1.3 \pm 0.5 ; P=.04)$, total bilirubin $(1.7 \pm 2.6$ versus $1.1 \pm 0.8 \mathrm{mg} / \mathrm{dL} ; P=.048)$, and brain natriuretic peptide (BNP) $(1277.9 \pm 1297.8$ versus 611.5 $\pm 292.8)$, and lower albumin $(3.7 \pm 0.5$ versus $3.4 \pm 0.6)$ and left ventricular end diastolic diameter (LVEDD) $(6.5 \pm 0.9$ versus $7.1 \pm 1.1)$ before LVAD implantation. Of the 81 patients who died, 9 required a right ventricular assist device (RVAD) support during HMII implantation, whereas none of the 26 surviving patients required such support $(P=.07)$. Nine patients are still receiving HMII support 5 years after implantation. 


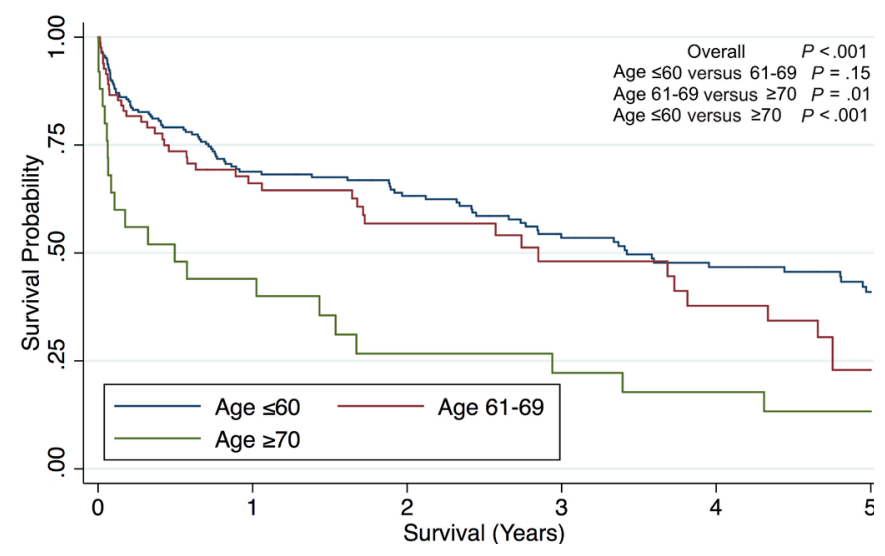

Figure 3. Kaplan-Meier survival analysis for patients aged older than 60 and older than 70 years.

Twenty-five patients ( 23 men, 2 women) were aged 70 years or older (range, 70-78 years) at LVAD implantation. Twenty-three of these patients died, $1(4 \%)$ is still receiving device support, and the other received a heart transplant after 498 days of LVAD support. The survival rate was $52 \%$ at 6 months (13/25) and $44 \%$ at 1 year (11/25). The longest survival time has been 3073 days. In this group, 8 patients were $\geq 75$ years old; 7 of them died; and 1 , our oldest LVAD recipient, aged 78 years, continues to receive HMII support.

\section{Adverse Events}

These recipients had a total LVAD support time of 178.7 cumulative patient-years (average of 1.7 years per patient). The most common adverse event was gastrointestinal bleeding (35 patients; 32.7\%) (Table 4). In 10 of these cases, the patients had arteriovenous malformations (AVMs), most of which $(\mathrm{n}=8)$ were bleeding from duodenal and jejunal AVMs; in the other 25 cases, bleeding was due to gastritis $(n=4)$, gastric and duodenal ulcers $(n=6)$, angiodysplasia $(n=5)$, diverticuolosis $(\mathrm{n}=5)$, or Mallory-Weiss tears $(\mathrm{n}=3)$; 2 patients had gastrointestinal bleeding from unknown location and of unknown etiology.

Twenty-four patients $(22 \%)$ required renal replacement therapy (RRT), and 8 (7.5\%) of them received RRT before HMII implantation. Five patients $(4.7 \%)$ had chronic stage $\mathrm{V}$ renal failure, had undergone hemodialysis for more than 1 year, and continued to receive RRT after LVAD implantation. Three patients $(2.8 \%)$ required continuous venovenous hemofiltration before LVAD implantation. Of the 14 survivors, 7 required RRT, 2 had chronic stage $V$ renal failure and continued to need hemodialysis after LVAD implantation, 3 recovered renal function with the support of RRT and were weaned from it during the 2 to 3 months after LVAD implantation, and 2 still require hemodialysis.

Eighteen patients (17.5\%) had ventricular arrhythmias; 14 of them had a history of arrhythmia, were taking antiarrhythmic agents, and had an automatic implantable cardioverterdefibrillator before LVAD implantation.

Twenty-four patients (22.4\%) had LVAD-related infections. Nine other patients $(8.4 \%)$ required RVAD support
Table 2. Cox Proportional Hazards Analysis for Independent Predictors of Mortality*

\begin{tabular}{lccc}
\hline Variable & Hazard Ratio & $P$ & $95 \%$ Confidence Interval \\
\hline Age >60 years & 1.60 & .006 & $1.15-2.23$ \\
Idiopathic etiology & 1.11 & .56 & $0.78-1.57$ \\
Hypertension & 1.16 & .37 & $0.84-1.60$ \\
Previous HM-XVE & 1.03 & .92 & $0.53-2.02$ \\
Previous cardiac surgery & 1.38 & .06 & $0.99-1.92$ \\
Blood urea nitrogen & 1.01 & .06 & $1.00-1.01$ \\
Albumin & 0.95 & .12 & $0.88-1.02$ \\
\hline
\end{tabular}

* Left ventricular ejection fraction and body mass index were removed from the model because of their having a variance inflation factor $>10$. HM-XVE, HeartMate XVE left ventricular assist device.

during HMII implantation, and 7 of these patients had a previous cardiac procedure. Moreover, an additional 28 (26.2\%) patients had neurologic complications.

\section{DISCUSSION}

In our study, we found that patients aged 60 years or older with severe heart failure can benefit from long-term continuous-flow LVADs and have a low incidence of adverse events. Our series is the longest involving this patient subgroup and has among the highest survival rates: $69 \%$ at 6 months, $63 \%$ at 1 year, and $54 \%$ at 2 years. In other studies of older LVAD patients, survival has ranged from $19 \%$ to $39 \%$ at 1 year [Jurmann 2004; Huang 2006; Sandner 2009; Drews 2010; Stepanenko 2010].

The shortage of donor organs and the correspondingly long wait times for heart transplantation mean that more elderly patients with end-stage heart failure are being referred to LVAD centers. However, clinicians may be less aggressive in treating these older patients, because they have a higher mortality rate. Of those in our study, all were in a critical hemodynamic state before LVAD placement. Sixtythree $(59 \%)$ were in INTERMACS profile 1 or 2 . Also, 52 patients (48.6\%) had undergone previous cardiac surgery, 54 $(50.5 \%)$ had been receiving IABP support, and 14 (13.1\%) had been receiving TandemHeart or Impella support before LVAD implantation. Thirteen (12.1\%) of the 107 patients had preimplantation hepatic dysfunction, and 12 had a liver biopsy during the HMII LVAD implantation procedure; in each case, pathologic examination revealed centrilobular congestion consistent with chronic congestive heart failure. During the HMII implantation procedure, 27 patients required a concomitant cardiac procedure, which is associated with increased multimorbidity in these patients [John 2014].

Multiple studies have identified age as an independent predictor of post-LVAD survival [Deng 2001; Jurmann 2004; Dang 2005; Holman 2009; Joyce 2009; Sandner 2009; Drews 
Table 3. Laboratory Data for 107 Patients during the 1-Year Follow-up Period*

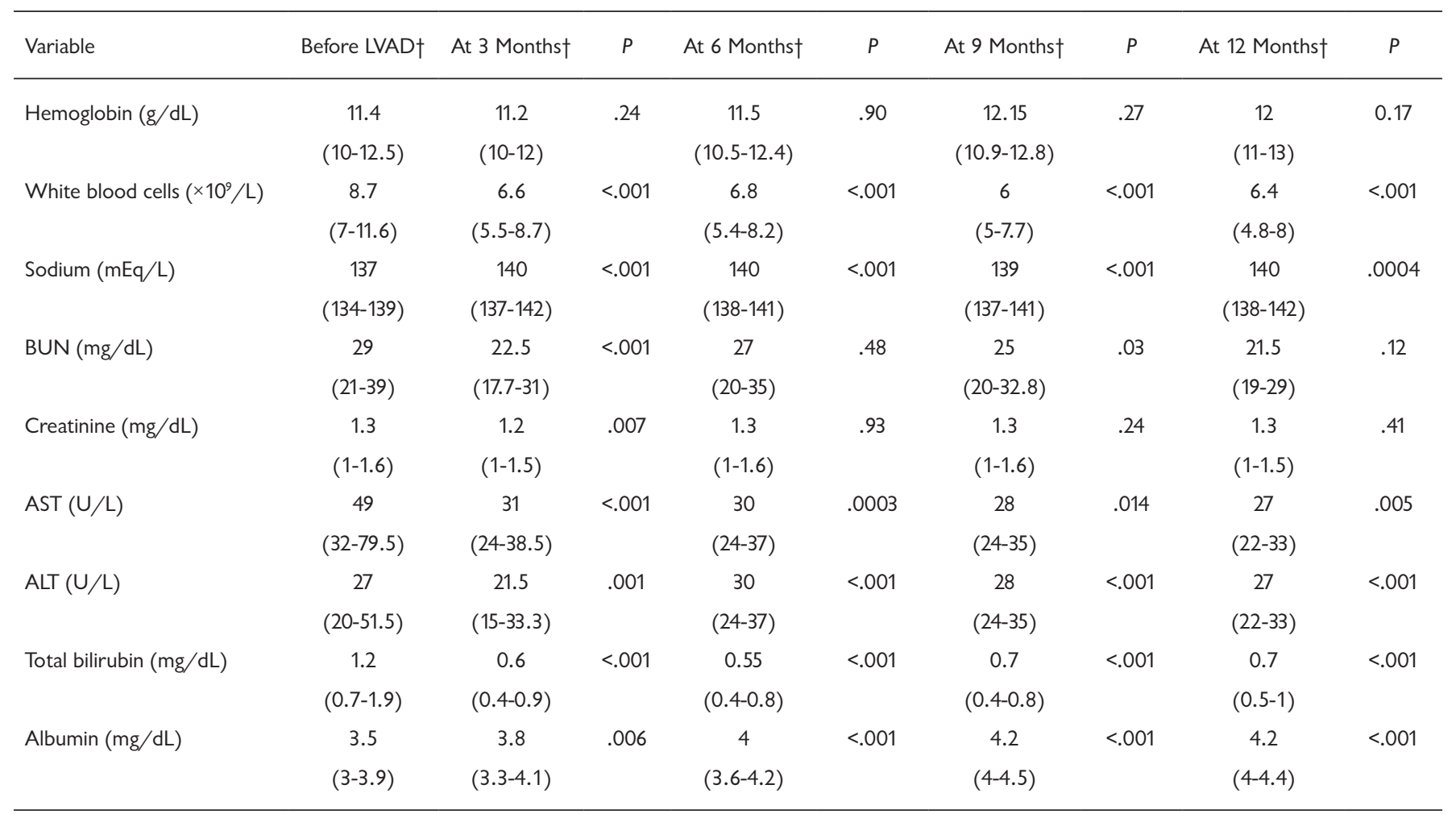

*AST, aspartate aminotransferase; ALT, alanine aminotransferase. $\mathrm{P}<.05$ was considered statistically significant.

†Data are given as median (25th-75th percentile).

2010; Kirklin 2011]. In studying 464 patients 65 years and older receiving the Novacor Left Ventricular Assist System (World Heart Inc., Oakland, CA, USA) for end-stage heart failure, Deng and colleagues found that older age was a significant risk factor for death. Another study showed that advanced age was an independent predictor of both early death and poor survival in 201 bridge-to-transplant patients with end-stage heart failure undergoing HeartMate LVAD implantation [Dang 2005]. In our study, LVAD recipients aged older than 60 years had worse 5 -year survival compared to their younger counterparts, and age $>60$ years was an independent predictor of mortality. However, further stratification of LVAD recipients demonstrated that the sexagenarian LVAD recipients had similar survival compared to their younger counterparts, whereas those 70 years and older had significantly poorer survival.

In 2004, Jurmann and colleagues reported that permanent mechanical circulatory support would likely evolve as a treatment option for selected end-stage heart failure patients aged 60 years and older and recommended that these patients be evaluated on a case-by-case basis [Jurmann 2004]. In 2010, researchers at the same center reported their overall experience; for the patients who received nonpulsatile LVADs, the hospital discharge rate was $19 \%$ at 1 year [Drews 2010].

The third INTERMACS report states that older age (60-70 years) is a risk factor for death in destination-therapy patients [Kirklin 2011]. However, the mean age of patients in the current study was $66 \pm 4$ years, the oldest being 78 years. In all, our study included 25 patients aged 70 years and older; their 6-month survival rate was $52 \%$, and their 1-year survival rate was $44 \%$.

Many of the previous studies were performed with firstgeneration pulsatile LVADs. These devices have now been replaced by newer, smaller, continuous-flow LVADs that have a compact design and involve a less-invasive surgical procedure, resulting in a faster recovery and shorter hospital stay. Results of recent studies more accurately reflect the better outcomes in older patients receiving these newer devices [Huang 2006; Kwon 2008; Kohmoto 2009; Sandner 2009; Drews 2010; Stepanenko 2010]. Kwon and coworkers reported that the mortality rate for patients older than 60 years is comparable to that for younger patients. Although Huang and colleagues observed a higher mortality rate after LVAD implantation in their older patients, the results did not reach statistical significance after being adjusted for various baseline differences [Huang 2006; Kwon 2008].

Stepanenko and associates showed that permanent LVAD therapy may be successful in highly selected elderly patients with terminal heart failure if the LVAD is implanted before cardiogenic shock or inotropic dependency ensues [Adamson 2011]. These older patients have a heightened incidence of comorbidities, including hypertension, 
Table 4. Postoperative Adverse Events*

\begin{tabular}{lccc}
\hline Adverse Event & Patients $\dagger$ & Events & EPPY \\
\hline Gl bleeding & $35(32.7 \%)$ & 45 & 0.25 \\
RRT & $24(22.4 \%)$ & 24 & 0.12 \\
Ventricular arrhythmia & $18(16.8 \%)$ & 18 & 0.09 \\
LVAD-related infection & $34(31.8 \%)$ & 121 & 0.68 \\
$\quad$ Pump pocket & $9(8.4 \%)$ & 19 & 0.11 \\
$\quad$ Drive-line & $11(10.3 \%)$ & 22 & 0.12 \\
$\quad$ Blood stream & $30(28.0 \%)$ & 75 & 0.42 \\
RV failure requiring MCS & $9(8.4 \%)$ & 9 & - \\
Neurologic complications & $27(25.2 \%)$ & 35 & 0.2 \\
$\quad$ Hemorrhagic & $15(14.0 \%)$ & 15 & 0.08 \\
Ischemic & $17(15.9 \%)$ & 20 & 0.11 \\
\hline
\end{tabular}

*EPPY, events per patient-year; GI, gastrointestinal; RRT, renal replacement therapy LVAD, left ventricular assist device; RV, right ventricular; MCS, mechanical circulatory support.

$\dagger$ Number of patients (\%).

diabetes mellitus, and a history of cardiac surgery and preimplantation circulatory support.

Adamson and colleagues observed no significant survival difference between patients who were $\geq 70$ versus $<70$ years old (1-year survival rate, $75 \%$ versus $72 \%$, respectively) [Adamson 2011]. Also, the average length of hospital stay was similar in both groups: $24 \pm 15$ versus $23 \pm 14$ days. These researchers believe that LVAD therapy improves the quality of life of older patients, their caregivers are more compliant with medications and instructions, and the patients do not have an increased rate of adverse events. The most frequent adverse event was hemorrhage requiring packed red blood cells and surgery.

In our current study, the most common adverse events were gastrointestinal bleeding and the need for RRT. Our patients had a high risk of postimplantation renal failure, with comorbidities such as hypertension $(68.2 \%)$, diabetes mellitus $(52.3 \%)$, a previous cardiac procedure $(48.6 \%)$, a previous LVAD (2.8\%), and IABP support $(50.5 \%)$ before HMII LVAD implantation. Nine patients $(8.7 \%)$ required RVAD support during the implantation procedure. It is important to note that 8 of 9 patients who required RVAD support died. This highlights the significant impact of RV failure on mortality especially in this elderly, high-risk subgroup of patients. This has an implication with respect to patient selection in patients aged above 60 years - to proceed with reluctance in patients who are high risk for post-LVAD RV failure.

Sandner and coworkers found that the glomerular filtration rate was significantly lower for LVAD patients regardless of their age, but $53.3 \%$ of their patients $\geq 60$ years old required RRT after LVAD implantation [Sandner 2009]. Genovese and colleagues found that the development of acute renal failure during LVAD support was associated with a significantly decreased survival rate- $30 \%$ at 1 year [Genovese 2010]. They report that renal failure is one of the predictors of 12 -month survival. We recently described the gradual recovery of renal function with RRT within 2 to 3 months after continuous-flow LVAD implantation [Demirozu 2011].

In a multi-institutional study of MCS, Holman and associates stated the importance of device- and patient-related infections as predictors of death [Dang 2005]. These researchers reported the following: infections are usually suppressed and managed with antimicrobial therapy, so patient deaths are then attributed to another cause, such as multiorgan failure or neurologic complications; however, as a common adverse event, infection is important and must be accurately stated as a risk factor for death after MCS therapy. We observed LVAD-related infections in 34 (31.8\%) of our 107 patients. In their $\geq 60$-year-old patients, Huang and colleagues observed a $23 \%$ rate of LVAD-related infections and a $61 \%$ rate of neurologic complications [Huang 2006]. Sandner and coworkers observed neurologic complications in $26.7 \%$ of their patients 60 years or older [Sandner 2009]. In our study, 27 patients $(25.2 \%)$ had neurologic complications.

In multiple studies, right-sided heart failure has been identified as a risk factor for death [Dang 2005; Morgan 2004; Ochiai 2002; Schenk 2006]. A longer duration of right-sided heart failure requiring inotropic support after LVAD implantation is associated with reduced survival to transplantation [Schenk 2006]. Sandner and colleagues reported that $10 \%$ of their older patients required RVAD support [Sandner 2009]. In our study, 9 patients (8.4\%) needed RVAD support during the LVAD implantation procedure; 7 of these patients had undergone previous cardiac surgery, and 4 of them required IABP support before LVAD implantation.

In previous studies of LVADs in older patients, the main cause of death was multiorgan failure [Jurmann 2004; Morgan 2004; Huang 2006; Holman 2009; Sandner 2009; Drews 2010; Stepanenko 2010]. In the present study, causes of death included previous secondary end-organ dysfunction, renal or hepatic dysfunction, sepsis, and neurologic complications related to multiorgan failure.

Joyce and colleagues compared 2 groups of patientsthose aged $\geq 65$ versus $<65$ years - and found that the younger patients were more likely to undergo LVAD implantation [Joyce 2009]. When these researchers compared patients who received LVADs and those who did not (because of therapeutic preference), patient age was a significant determining factor. Medical therapy was the preferred treatment for patients older than 65 years. However, the REMATCH (Randomized Evaluation of Mechanical Assistance for the Treatment of Congestive Heart Failure) trial showed a significant reduction in the risk of death among patients aged 60 to 69 years in the device group compared with the medical group [Rose 2001] Therefore, any differences in LVAD therapy with regard to patient age are likely the result of the clinician's decision to refer patients for LVAD implantation as a bridge to transplantation or as destination therapy. The adverse effects of advanced age on the survival of LVAD patients are not easily modified but can be managed by experienced clinicians. 
Twenty-eight of our patients underwent heart transplantation, with a median wait time of 473.5 days after HMII LVAD implantation and $75 \%$ survival more than 1 year later. Sandner and colleagues reported a 1-year survival rate of $90 \%$ for their LVAD patients 60 years or older who later underwent transplantation [Sandner 2009].

Renal dysfunction is one predictor that may affect survival in these older patients, causing hemodynamic instability. For this age group, we believe that individual consideration is required so that end-organ dysfunction, right ventricular failure, and inotropic dependency do not interfere with recovery.

The limitations of this study include those related to any retrospective analysis: it is not a prospective or randomized study. In addition, our data represent our experience with a single device. Other researchers have reported their experiences with various continuous-flow pumps in patients of advanced age [Deng 2001; Jurmann 2004; Huang 2006; Sandner 2009; Drews 2010; Stepanenko 2010]. Furthermore, the HMII recipients in our study were primarily males who have demonstrated significantly better outcomes compared to women [Magnussen 2018], which may limit the generalizability of our study.

In conclusion, our experience shows that advanced age should not preclude patients from receiving LVAD therapy and that these patients can benefit from long-term continuous-flow LVAD therapy, which preserves their end-organ function while they await heart transplantation.

\section{ACKNOWLEDGMENTS}

The authors receive research support from Medtronic, Inc. and Abbott, Inc.

\section{REFERENCES}

Adamson RM, Stahovich M, Chillcott S, et al. 2011. Clinical strategies and outcomes in advanced heart failure patients older than 70 years of age receiving the HeartMate II left ventricular assist device: a community hospital experience. J Am Coll Cardiol 57(25):2487-95.

Dang NC, Topkara VK, Kim BT, Mercando ML, Kay J, Naka Y. 2005. Clinical outcomes in patients with chronic congestive heart failure who undergo left ventricular assist device implantation. J Thorac Cardiovasc Surg 130(5):1302-9.

Demirozu ZT, Etheridge WB, Radovancevic R, Frazier OH. 2011. Results of HeartMate II left ventricular assist device implantation on renal function in patients requiring post-implant renal replacement therapy. J Heart Lung Transplant 30(2):182-7.

Deng MC, Loebe M, El-Banayosy A, et al. 2001. Mechanical circulatory support for advanced heart failure: effect of patient selection on outcome. Circulation 103(2):231-7.

Drews T, Stepanenko A, Dandel M, Buz S, Lehmkuhl HB, Hetzer R.
2010. Mechanical circulatory support in patients of advanced age. Eur J Heart Fail 12(9):990-4.

Genovese EA, Dew MA, Teuteberg JJ, et al. 2010. Early adverse events as predictors of 1-year mortality during mechanical circulatory support. J Heart Lung Transplant 29(9):981-8.

Holman WL, Kormos RL, Naftel DC, et al. 2009. Predictors of death and transplant in patients with a mechanical circulatory support device: a multi-institutional study. J Heart Lung Transplant 28(1):44-50.

Huang R, Deng M, Rogers JG, et al. 2006. Effect of age on outcomes after left ventricular assist device placement. Transplant Proc 38(5):1496-8.

John R, Naka Y, Park SJ, et al. 2014. Impact of concurrent surgical valve procedures in patients receiving continuous-flow devices. J Thorac Cardiovasc Surg 147(2):581-9; discussion 589.

Joyce DL, Conte JV, Russell SD, Joyce LD, Chang DC. 2009. Disparities in access to left ventricular assist device therapy. J Surg Res 152(1):111-7.

Jurmann MJ, Weng Y, Drews T, Pasic M, Hennig E, Hetzer R. 2004. Permanent mechanical circulatory support in patients of advanced age. Eur J Cardiothorac Surg 25(4):610-8.

Kirklin JK, Naftel DC, Kormos RL, et al. 2011. Third INTERMACS Annual Report: the evolution of destination therapy in the United States. J Heart Lung Transplant 30(2):115-23.

Kohmoto T, Osaki S, Johnson MR, et al. 2009. Improved outcomes after ventricular assist device implantation in patients older than 60 years of age. J Heart Lung Transplant 28(2 suppl):S134.

Kwon MH, Moriguchi JD, Plunkett MD, et al. 2008. Impact of age on outcomes of ventricular assist devices utilized as bridge to cardiac transplantation. J Heart Lung Transplant 27(2 suppl):S120.

Magnussen C, Bernhardt AM, Ojeda FM, et al. 2018. Gender differences and outcomes in left ventricular assist device support: The European Registry for Patients with Mechanical Circulatory Support. J Heart Lung Transplant 37(1):61-70.

Morgan JA, John R, Lee BJ, Oz MC, Naka Y. 2004. Is severe right ventricular failure in left ventricular assist device recipients a risk factor for unsuccessful bridging to transplant and post-transplant mortality. Ann Thorac Surg 77(3):859-63.

Ochiai Y, McCarthy PM, Smedira NG, et al. 2002. Predictors of severe right ventricular failure after implantable left ventricular assist device insertion: analysis of 245 patients. Circulation 106(12 suppl 1):I198-202.

Rose EA, Gelijns AC, Moskowitz AJ, et al. 2001. Long-term use of a left ventricular assist device for end-stage heart failure. N Engl J Med 345(20):1435-43.

Sandner SE, Zimpfer D, Zrunek P, et al. 2009. Age and outcome after continuous-flow left ventricular assist device implantation as bridge to transplantation. J Heart Lung Transplant 28(4):367-72.

Schenk S, McCarthy PM, Blackstone EH, et al. 2006. Duration of inotropic support after left ventricular assist device implantation: risk factors and impact on outcome. J Thorac Cardiovasc Surg 131(2):447-54.

Stepanenko A, Potapov EV, Jurmann B, et al. 2010. Outcomes of elective versus emergent permanent mechanical circulatory support in the elderly: a single-center experience. J Heart Lung Transplant 29(1):61-5. 